\title{
Learning Topics in Urban Planning at UFMG: Geoprocessing to Support Analysis, Planning and Proposal of the Urban Landscape at Neighborhood Scale
}

MOURA, Ana Clara Mourão

\section{Resumo}

Relata experiência de treinamento de alunos em geotecnologias para apoio a processos de análise, planejamento, e proposição de paisagens urbanas em escala local, usando Análise de Multicritérios para identificação de potencialidades, vocações e conflitos de interesse no uso do solo. São construídas sínteses de interesse ambiental, de adensamento urbano, e de conflitos de interesse. A representação tridimensional do território é para apoio à proposição do zoneamento. Os alunos atuam de modo mais consciente quando projetam, usando estudos preditivos para a paisagem, pois conseguem visualizar as consequencias das proposições para o espaço urbano e observar as consequências sobre as mudanças climáticas.

Palavras-Chave: Parâmetros urbanísticos; Simulação de Planejamento da Paisagem; Modelagem Parametrizada da Paisagem Territorial.

\begin{abstract}
Reports the experience of training students in the use of geotechnologies to support analysis, planning and proposal of the urban landscape at neighborhood scale, using Multi-Criteria Analysis for identification potentials, vocations and conflicts of interest in land use. They built Environmental Interest Synthesis, Urban Occupation Synthesis, and Conflicts of interest Synthesis. The three-dimensional representation of the territory was used to support the proposed zoning. Students act in a more conscious manner when creating projects, undertaking predictive studies on the landscape, since they are fully able to understand the consequences of the intervention on urban spaces and observe climatic changes.
\end{abstract}

Keywords: Urban Parameters; Landscape Design Simulation; Parametric Modeling of Territorial Occupation. 


\section{Introduction}

It's important to introduce a timeline: the evolution and current conditions of geotechnology for the management of urban space and the proposal of learning topics of urban planning at the School of Architecture, UFMG, Brasil.

We are living in a odd time for urban spatial analysis, when information technology, and especially of georeferenced information, begins to be largely dominated by sector users, allowing us to use it, in fact, as a tool for diagnosis and application of models predictive, to support decision-making. Besides the maturation in using the tools, we are initiating a new paradigm in spatial analysis and representation, marked by the principles of interoperability between systems, strong investment in communication and provision of tools for projectual propositions simulated in real time.

The present time is a result of the experiences in the past 25 years in urban and environmental studies using geotechnologies. Notwithstanding the use of geotechnology, through the creation of Geographic Information Systems has begun in some countries still in the 60 s, we can say that the use of geoprocessing begins, indeed, more widely in Brazil in the late 80s.

The Geographic Information Systems presents the classical models of combination of variables for facilitated application to map algebra, or allow users to propose their own models, the decomposition of variables into arrays and logical development of combination between them. These process has been so expressive that generated specific software for the employment of certain models, so-called Expert Information Systems. The development of spatial analysis from these new features was significant, but still kept the paradigm of decomposing to compose, to represent and analyse the territory in variables or principal components and to promote the integration of these in order to reproduce the complexity of reality. Once reproduced the territory and its complexity satisfactorily, even though with cutouts simplification inherent in models, the users had in hand a digital tool that compose a virtual mirror of the territory, that makes possible simulate changes, to build transformations predicts, and to understand values and broadcasts phenomena.

The actual moment is particularly interesting because many users are already using the geoprocessing tools for the collection, storage, representation and analysis of georeferenced data. The Geographic Information Systems and their tools are now widely available and are used to support decision making. It is necessary to emphasize that GIS offers no unique answers or un- questionable results for space studies, but presents points of view, governed by different criteria, which are only to support the decisions because, ultimately, the decisions are still the responsibility of the specialist who chooses and justifies his choices.

For correct use of GIS in spatial analysis, the first step, and one of the most important, is the clear definition of objectives. The mature definition of objectives will guide the choice of variables, the spatial analysis models to be used, and will validate or not the responses obtained. In this sense, the procedures supported by geotechnologies are ways of having reproducible criteria for performing spatial analysis.

The recent scenario was then recognition of the potential of Geographic Information Systems, the strength of the processes of communication and exchange of information and the existence of initial legislation supporting to the dissemination of information. In a process that is increasingly integrated and global, geotechnology tools now have to answer to the following values: widespread condition of communication with different sectors of users, wide interoperability conditions, and promoting broad systemic approach for process modeling and construction of interpretive portraits of reality and the simulations of its changes.

The new technological conditions will support, especially, territorial governance processes, as they will act as a bridge of communication between the technical sectors, administrative sectors and the community, as the new occupation and uses of the territory can be simulated, discussed and communicated properly. It's a is a further step for participatory planning, because there will be broader understanding of the condition and proposed regulations. It is a hope that science and technology will be called to cooperate in decision making and ensure that the anthropic occupation of the environments will seek dynamic equilibrium.

We believe and defend that the application of geotechnologies on urban planning provides the methodologies and tools to give support to decision making, especially to respect environmental limits and consider climatic changes on the territory.

We are developing tutorials, exercises and case studies in order to teach the new urban planners how to simulate the results of theirs proposals and be more conscientious about the landscape and land use planning. That is the way that we believe the professionals can work using the best supports to respect the variables related to climatic changes. 


\section{Geoprocessing on Urban Planning Workshop: Local Planning Problems}

Recently, a new Architecture and Urbanism night course was created at the Escola de Arquitetura, Universidade Federal de Minas Gerais (Architecture School at the Federal University of Minas Gerais). Since it emphasizes urban planning, it differs from the daily course, which has a focus on building project. This new emphasis makes fundamental that students familiarize themselves with geoprocessing tools, in order to acquire abilities that will make them able to: present their planning in a georeferenced manner, use satellite images, treat images with digital processing for territorial and urban planning, explore resources from Geographic Information Systems and, specially, develop analyses and representation models for urban spaces.

As an example of the course's goals, we present the experience of the thought module "Urban Planning Workshop: Local Planning Problems", discussing issues to a district scale. The students were involved in gathering primary data, examining the data regarding its spatial components, and afterward proposing a settlement type that would model urban landscape in a sustainable manner, respectful to community values and to the environment. Geoprocessing is a fundamental tool in mapping territorial characteristics and investigating conflicts of interest within a specific area, using multi-criteria analyses.

This module holds as pedagogical aims: the construction of a conceptual base for studies on landscape, environment, planning, and spatial perception; training on survey activities; storage, treatment, and representation of spatial data; tuition on spatial analyses methodology; diagnostics, prognostics and propositions of spatial intervention, with the use of geoprocessing; and, finally, the study of public policies and legislations regimenting urban settlements, regarding their contexts.

We picked the Vale do Sereno district, which is located in a frontier area between two municipalities: the Minas Gerais state capital municipality, Belo Horizonte, and the Nova Lima municipality
(Figure 1). The district is still not densely populated, but it suffers from an expressive pressure for urban transformation and growth, and it is being heavily impacted by vertical growth and by the settlement rate, despite its conflicting principles to environmental interest and to the preservation of what is a notable landscape. Reasons for this growth reside in its being the most economically interesting region for selling real estate within the Metropolitan Region (Região Metropolitana - RMBH) of Belo Horizonte, and since urban regulations (presented at the development plan of Nova Lima) authorize this intense growth and transformation on the urban landscape.

This study was undertaken using Multi-criteria Analyses, spatial perception research, and proposition of a settlement typology, which considers existing conflicts and local landscape context. The students were instructed to use geotechnologies as a support tool for visualizing and communicating their urban intervention proposals, also simulating their effects on the resulting landscape.

\subsection{Methodology for Urban Planning, supported by geoprocessing - Multi-criteria Analyses}

With the aim of making maps Environmental Interest Synthesis and Urban Expansion Interest Synthesis, different variables where selected for each (Figure 2). Variables were mapped initially as ordinary themed maps, which were later turned into potential surfaces for the theme's distribution, according to their relevance for each of the syntheses. A Decision Tree is built as a flowchart combining variables through map algebra. In this specific work, the algebra used was pondered average, by giving weights for combined variables and grades for their legend components.

In order to allocate weights, which demonstrate the relative importance of each variable to the analyses, we chose to undergo a consultation, aiming to obtain an opinion average, for maximizing the consensus using the Delphi method.

The process was organized in the following manner: the students gave their individual opinions on

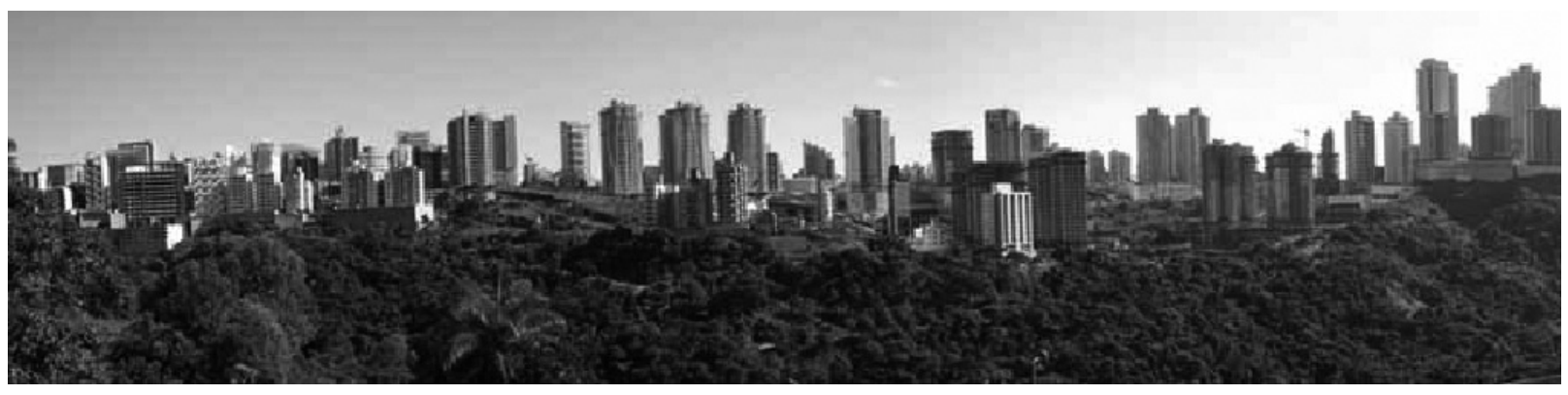

Figure 1: "Vale do Sereno" Landscape - expressive settlement growth 


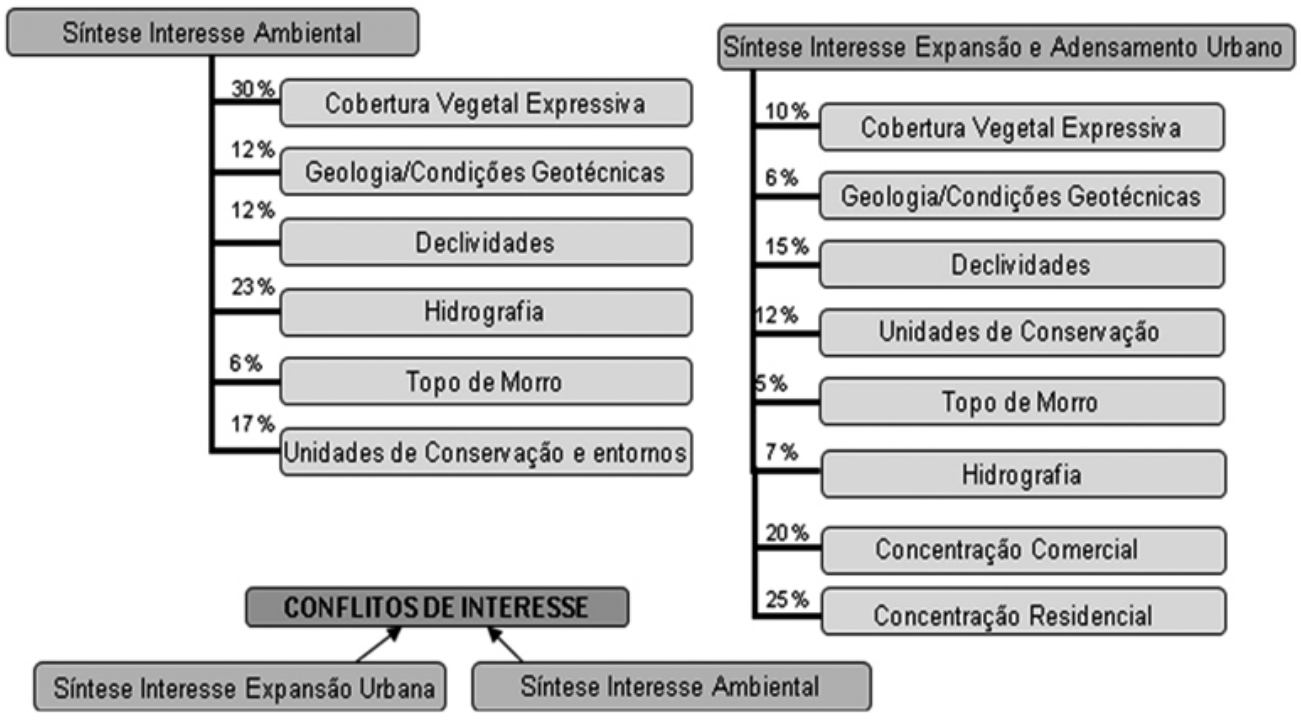

Figure 2 - Decision Tree for structuring Environmental Interest Synthesis, Expansion Interest and Urban Density Synthesis, and Conflicts of interest Synthesis

the hierarchical position of each analyses variable. After the gathering of opinions, we presented the opinion average and mode to the group, and each individual gave out a second opinion, altering or not their first one. Then, a new medium was calculated, being then used as a reference for the variable's weights. This process is known as "knowledge driven evaluation," meaning the incorporation of opinions gave out by informed people regarding the situation under evaluation, about specific aspects of the phenomena and their variables.

The students, since they participated in field work and interviews with locals, had knowledge on the factors interfering in the area's characteristics. It is considered that 'the specialists view is calibrated' and, also, that statistically speaking, the higher the number of variables, the smaller will be the probability of a random result, since fluctuation decreases.

Grades, in turn, are values attributed to each legend component within themed maps, defined according to the relevance degree each variable/ occurrence holds, and regarding a specific goal. In the case of the Need for Environmental Protection synthesis, grades meant how much each spatial occurrence is important for preservation. As for the Expansion Interest and Urban Density Synthesis, grades attributed show how much each spatial occurrence is adequate for population density and settlement

Once partial Need for Environmental Protection synthesis and Expansion Interest and Urban Density Synthesis are created, it is beneficial for the urban planner to compare the analyses, in a way to identify potential transformations, conflicts of interest, and new land use possibilities.

\subsection{Identification of potentials and conflicts of interest}

Information layers of each analysis goal were generated for identifying environmental and urban expansion interests. Each layer was transformed into a potential surface for specific variable distribution, according to their importance for each analysis' goal. These layers were then combined by multi-criteria analysis, which generated partial syntheses. This, in turn, allowed for the identification of possibilities and conflicts of interest.

\subsubsection{Environmental Interest Synthesis}

Through the same procedure used for urban expansion interest synthesis, an environmental interest synthesis was generated. The variables which are most decisive in environmental condition interests were identified, and information plans were created for each variable:

a. Vegetation cover - Map obtained through orthophotograph classification. The area presents a rich vegetation cover. The classification credited a grade 10 for areas with vegetation cover and 0 for areas without it.

b. Geology / geotechnical conditions -A study was developed using considering adequateness to urban settlement and the need for protection due to settlement risks as criteria.

c. Declivity - Based on Digital Elevation Model of Aster images, and classified by bands of 0 to $5 \%, 5$ to $30 \%, 30$ to $47 \%$, and above $47 \%$. Declivities above $47 \%$ are considered to present higher preservation interest, followed by declivities of 30 to $47 \%$, while low declivity areas are more subject to flooding. Declivity 
bands of 5 to $30 \%$ are not an environmental priority, according to the approach using this variable.

d. Hydrography - Its map was created from the location and attribution of water bodies' control bands.

e. Hilltop-Hilltops, represented on the altimetry by the last third sub-basin, are considered environmental protection areas and restricted for settlement.

f. Conservation units - The area studied is located near two conservation units: an Ecological Station and a RPPP (Permanent Private Patrimony Reserve). The last is an environmental passive held by a mining company and the ecological station protects water abstraction areas for the surroundings consumption.

g. Environmental Interest Synthesis Map Once maps were created, they underwent through a multi-criteria analyses, according to values defined by specialists, using the Delphi method. The weights attributed for each layer were: Hydrography, 23\%; Conservation Units and their surroundings, 17\%; Geology/Geotechnical Conditions, 12\%; Expressive Vegetation Cover, 30\%; Hilltop, 6\%; Declivities, 12\%. (Figure 3).

\subsubsection{Expansion Interest and Urban Density \\ Synthesis}

Spatial analysis procedure identified variables which are most decisive in urban settlement interest, and promoted the creation of information plans of each variable. Information layers were translated through matrixes, with 10 meters resolution and legend values meaning the relevance degree, graded from 0 to 10 .

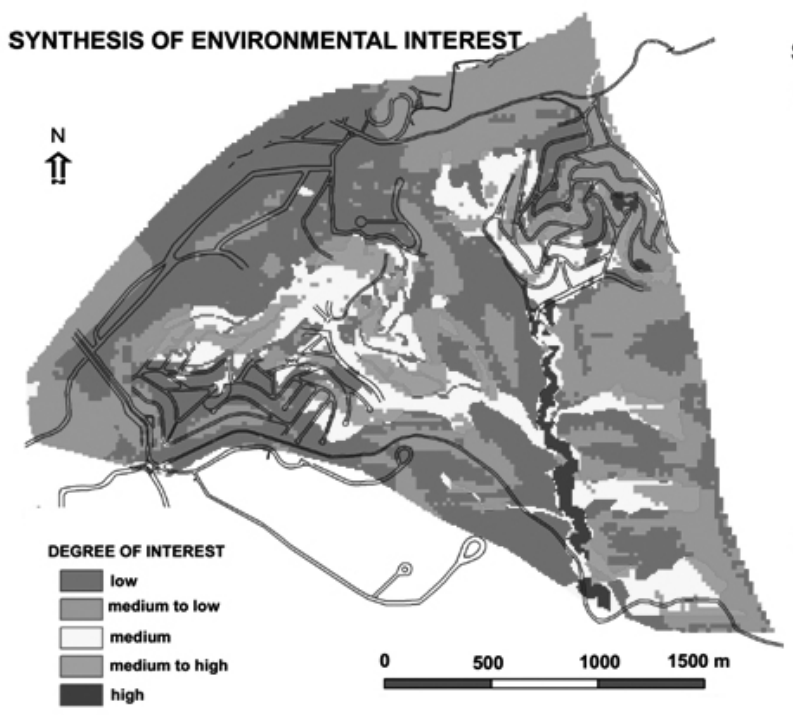

a. Vegetation cover - Map obtained through orthophotograph classification. We observe that an expressive vegetation cover is understood and classified as an impeding factor to urban interest.

b. Geology / Geotechnical Conditions - A study was developed using considering adequateness to urban settlement.

c. Declivity - created from the digital elevation model of Aster images, and classified by bands of 0 to $5 \%, 5$ to $30 \%, 30$ to $47 \%$, and above $47 \%$. Settlement conditions were evaluated regarding flood risks, without risk, medium risk not suitable for building.

d. Residential Density -From points of residential land use, Kernel's density model was used, and different degrees of this type of settlement were defined in bands. Considering that there is a greater interest in living in already consolidated settlement areas, we used the distance from these settlement clusters as criteria for this band grading.

e. Commerce and services cluster -From points of commerce and services clusters, Kernel's density model was used, and different degrees of this type of settlement were defined in bands. Considering that there is a greater interest in living in areas providing commerce and services, we used the distance from these settlement clusters as criteria for this band grading.

f. Conservation Units - The RPPP (Permanent Private Patrimony Reserve) and the EE (Ecological Station) were considered with restrictions to settlement.

g. Hydrography - For water courses and their head are areas of permanent protection (APPs) and may not comprise a settlement.

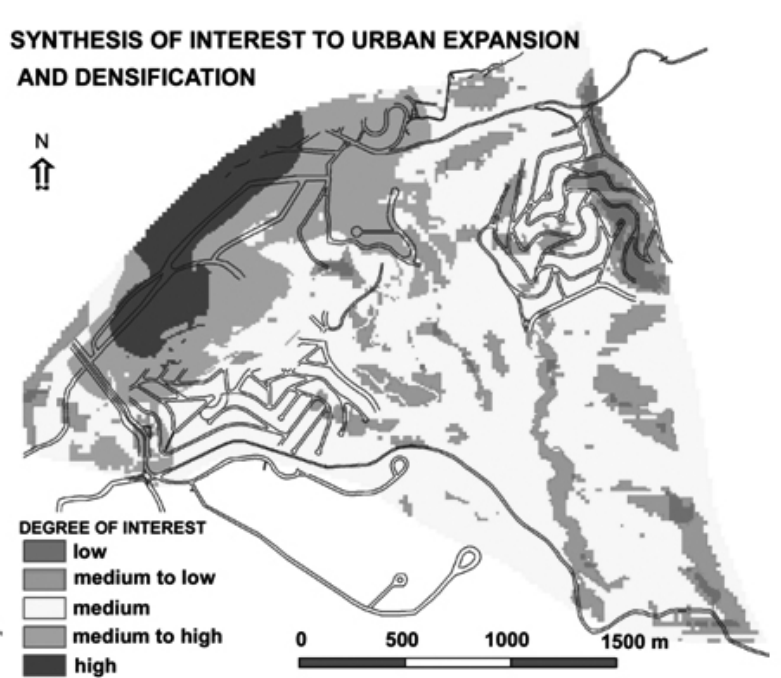

Figure 3 - Need for Environmental Protection synthesis \& Urban Expansion Interest Synthesis 


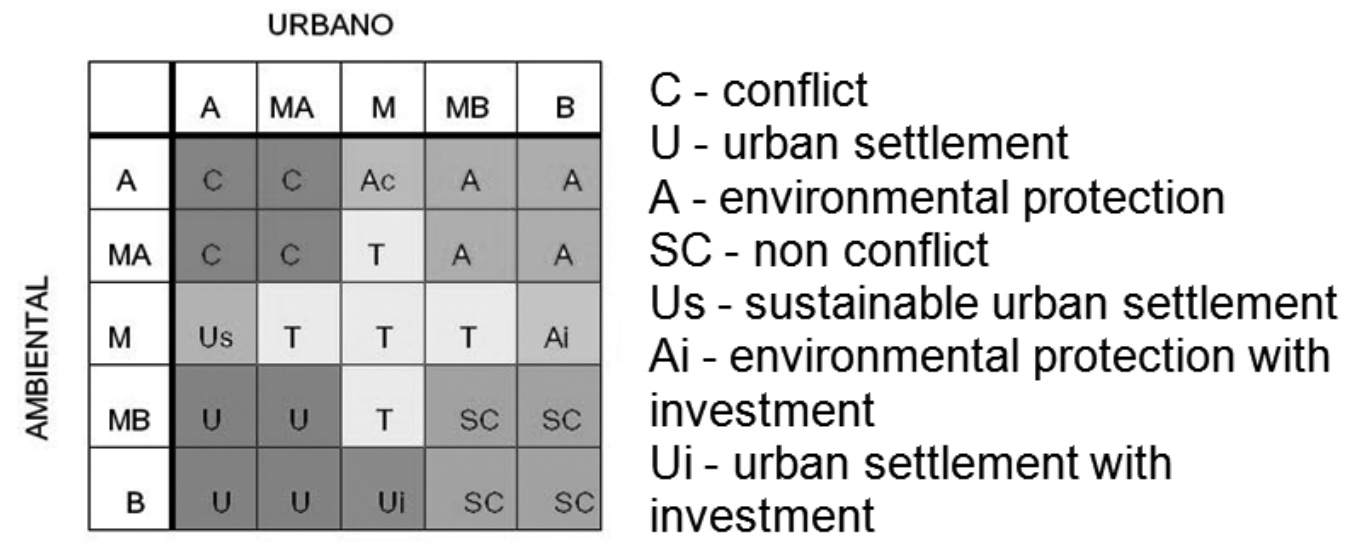

Figure 4 - Combination Matrix Conflicting Interests - Urban \& Environmental Interests

h. Hilltop - Hilltops, represented on the altimetry by the last third sub-basin, are considered environmental protection areas and restricted for settlement.

i. Urban Expansion Interest Syntheses Map Once the maps were created, they underwent through a multi-criteria analyses, according to values defined by specialists, using the Delphi method. The weights attributed for each layer were: Hydrography, 7\%; Conservation Units and their surroundings, 12\%; Geology/Geotechnical Conditions, 6\%; Expressive Vegetation Cover, 10\%; Hilltop, 5\%; Declivities, 12\%, Residential Cluster, 25\%; and Commerce and Services Cluster, 20\%. (Figure 3).

Once the syntheses for urban expansion interest and for environmental interest were created, they were compared in order to promote the identification of areas where settlement potential is clearly defined, where there are conflicts of interest, as

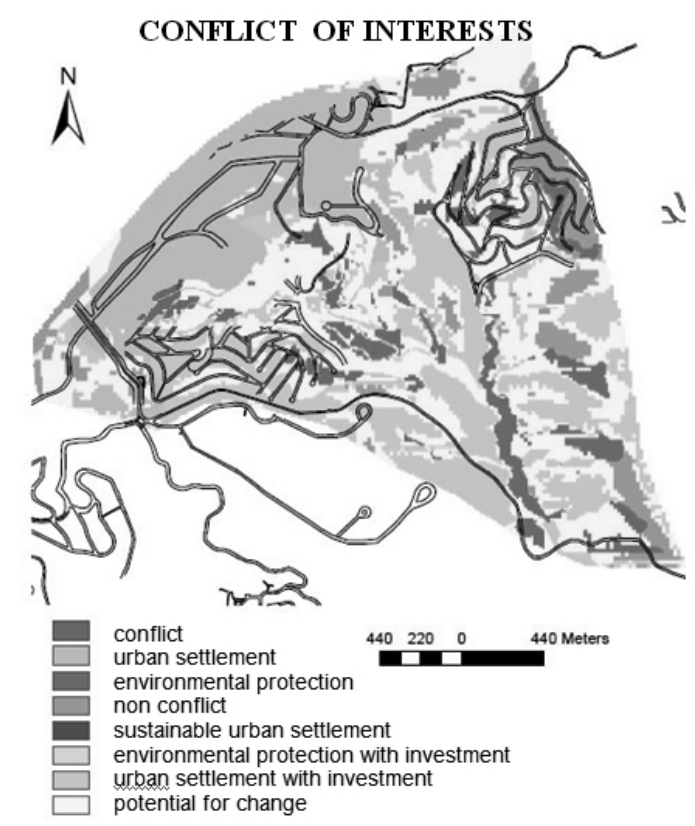

Figure 5 - Mapping of Conflicts, Possibilities and Potentials well as were there are specific conditions of interests and potentials.

The logic used in this analysis is also matrix analysis, for which possible combinations are identified, and the results obtained (Figure 4).

It is observed that there are combinations with clear interest predominance, either environmental or urban settlements. In opposed conditions, there are areas presenting medium to high interest, both environmental and urban, generating conflicts. On the other hand, there are also areas of no conflict, presenting medium to low urban or environmental interests. Decisions regarding conflict areas are left to be resolved within politics, or by clear definition of interest priorities, what can be widely justified and discussed. Areas presenting no conflicts of interest are indicated to be utilized for other needed uses, potentially generating conflict if located in other areas, such as land fillings, industrial parks, recycling stations, etc. (Figure 5).

There are regions where there is a medium interest in environmental preservation and low urban interest, which defines them as environmentally interesting, but with need for recuperation investments. Also, there are regions where there are regions where there is high environmental interest and medium urban interest, which defines them as environmentally interesting, but monitoring and maintenance are needed, since there is some degree of urban interest and consequent pressure.

On the other hand, there are regions presenting medium urban interest and low environmental interest, what defines them as presenting an urban interest, but still with the need for investments to make them properly attractive. There are also regions presenting high urban interest and medium environmental interest, what defines them as urban interested regions, but still of sustain- 

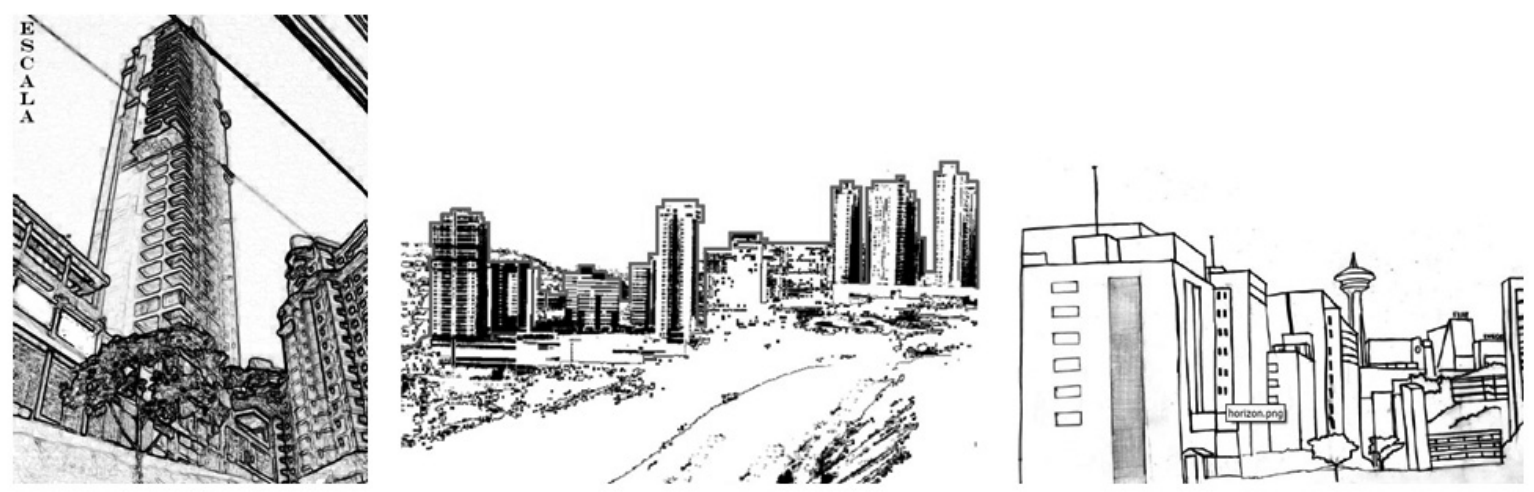

Figure 6 - Drawings representing landscape's essence

able use, once environmental issues still must be considered. These areas present potential for being Environmentally Protected Areas (Áreas de Proteção Ambiental - ASPAs).

In cases where an area presents medium interests for both urban settlements and environmental preservation, they are classified as transitional or as having transformation potential. They are significantly interesting for territorial planning, since when transformed they do not generate conflicts, but possibly generate irradiating results.

\section{Studies on Landscape Perception as an Assistance Tool for Image Planning}

Once the area is characterized according to their potentials, restrictions, possibilities and conflicts of interest, we moved on to the next step. Landscape perception interpretation and representation was undertaken, according to Spatial Perception and Cognition theory. The goal was to lay a foundation for the following phase, which was a project for land use and projection of the resulting new landscape for the district. This stage aimed to understand not only values involved, not only from the technical point of view, but also regarding landscape identity values.

As theoretical bases, classical authors were discussed, such as Kevin Lynch (1997), with The image of the city, and Gordon Cullen (1983), with Urban Landscape. Lynch's readings gave helped them perceive place through their structuring elements, mental map creation, legibility conditions, landscape identity and singularity. Cullen's readings instigated identification of place's cognition, considering one's insertion in a landscape and the proximity of all points of view that it encompasses. Both approaches facilitated them to identify the district's genius loci, what characterizes its landscape, what is valued by the community, and must be considered by urban projects.
In order to students benefit the most, we used field work, interviews with the community, and the making of expressive images, both by hand drawings and digitally altered photographs, capturing the landscape's place essence. (Figure 6).

\section{Conclusions - Urban Zoning Proposals and the Parametric Modeling of Territorial Occupation}

The drawing and landscape perception field step was important to slow down the time spent in observing and apprehending landscape, while the students understood their main characteristics and values, they could also mature their reflections on their urban zoning proposals.

The project proposals again face them with geotechnologies, since we required from them that all processes were undertaken in tridimensional representations, in a way they could have control over their project proposals, develop more effective forms of communication to locals, and simulate their results for prediction studies.

The students presented, as final products, maps specifying the zoning proposed for the district, justifying each settlement type, regarding previous analyses. Along with this map, they also made tables presenting urbanistic parameters indicated for each zone, such as: minimal plot size, building setbacks, maximum building rate, land use coefficient, maximum building height, terrain quota by habitation unit, plot's permeability rate, etc. In order for them to control their propositions, we asked them to attach tridimensional simulation drawings to the tables, so that they would really understand the meaning of those values, within a prognostic study of landscape intervention (Figure 7).

The students worked in tridimensional models during all the process, in order to simulate their proposals over urban landscape. Through tridimensional landscape simulation, it is possible to 

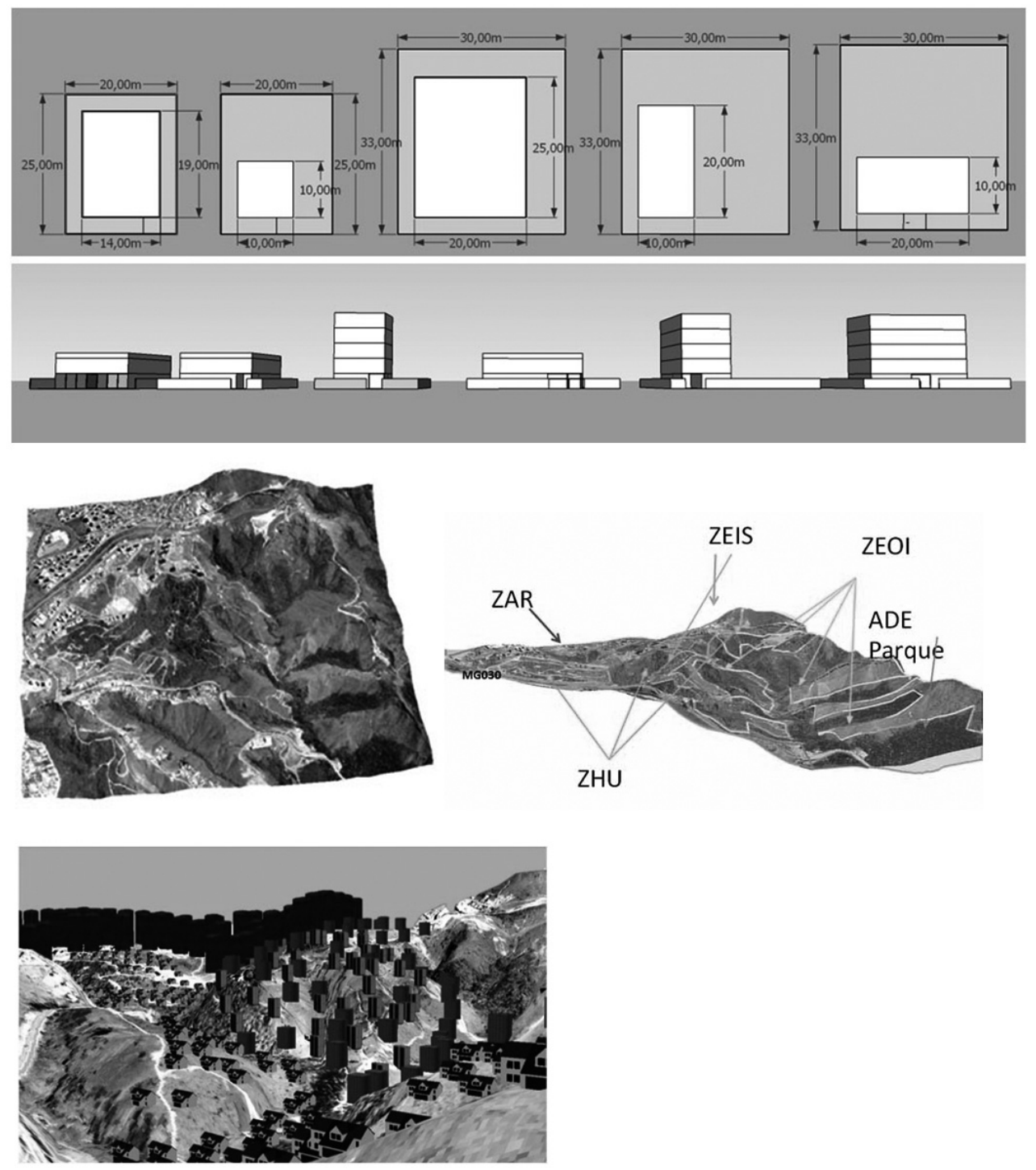

Figure 7 - Urban Parameters - Simulation of landscape intervention

predict possible consequences of the urban parameters proposed by zoning. (Figure 7)

The main goal of investments made towards geotechnologies is the increase of communication with local communities, hoping to make the results of Municipal Development Plans and Urban Occupancy and Zoning Laws comprehensible. This allows the community to place themselves as fundamental agents in the production of their own urban space. And as for the Urban Planner and Architects under formation, our expectation is that they will act in a more conscious manner when creating their projects, undertaking predictive studies on the landscape, since, only then, they are fully able to understand the consequences of their intervention on urban spaces.

Since we have explained the students the importance for the urban planner to have dominion over the landscape proposal that he designed, to achieve to simulate the consequences of proposed urban parameters, we decided to investigate geotechnologies that give support to this process.

After understood the moment that we are in the employment of geotechnology, as discussed in the introduction of this article, we identified that we are in the doors of a new paradigm in the representation of territorial landscape: the combination of values of GIS (Geographic Information System) with the BIM (Building Information Modeling), and the importance of promoting the following features: wide interoperability, expressive communicability condition and excellent graphical interface for different users involvement, employment of what we decided to denominate "Parametric Modeling of Territorial Occupation".

In search of tools that could support us to take these new concepts and values to the students, we identified new software in the market, and we are living the experience of using a parameterized model to make simulations in real time, testing the results from the urban landscape applications and parameter settings. (Figure 8 ). 

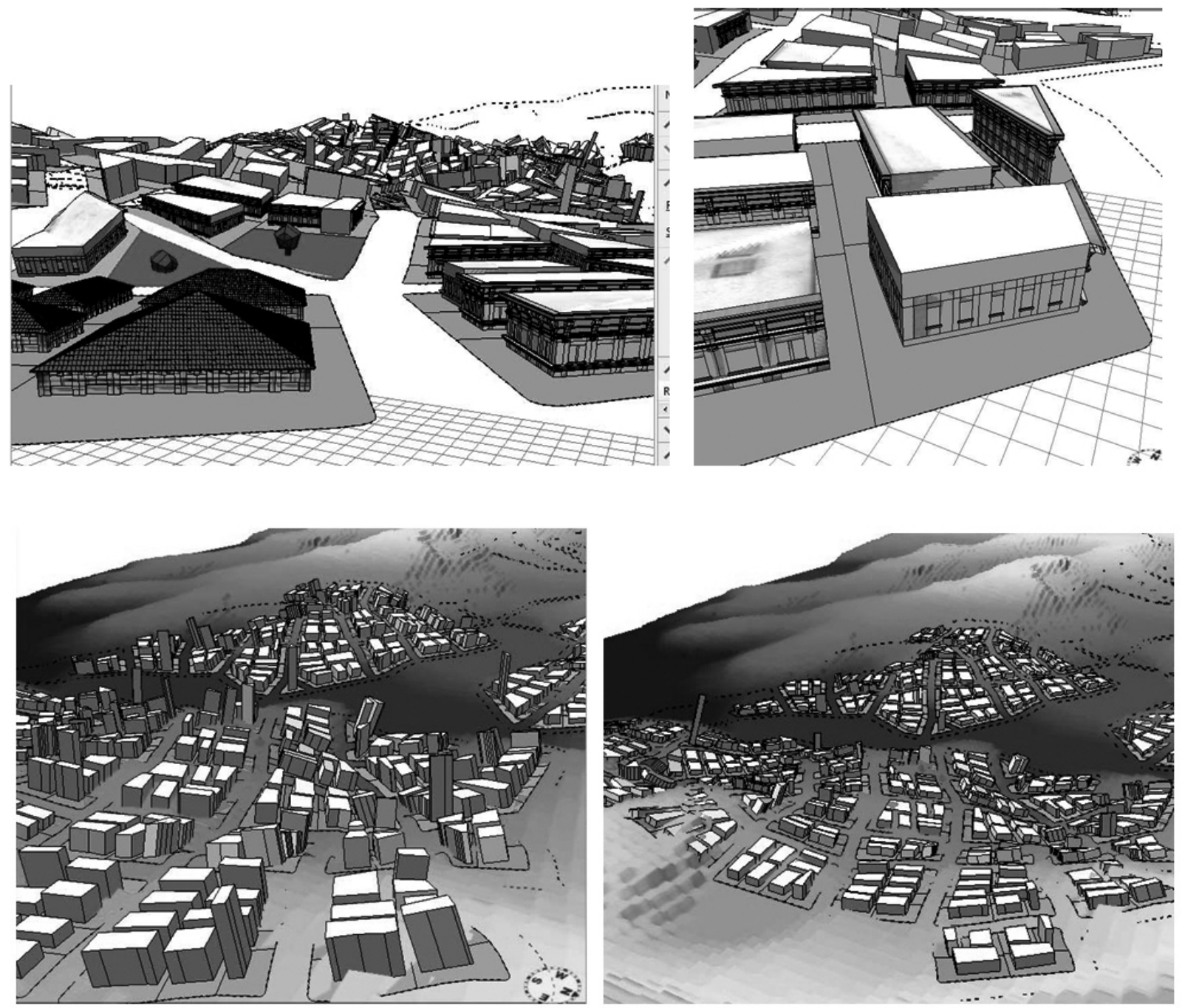

Figure 8 - Urban Parameters - Application of Rules in Parametric Modeling of Territorial Occupation

The applications available today are not yet fully ready to be used in urban planning, since they were originally created for use in games, and there is still a long and demanding work to decode the thinking of urban regulations for the simulation in augmented reality, and promotion of its variations in real time. The GIS Lab team at the School of Architecture from the Federal University of Minas Gerais is committed to building scripts that translate the rules of composition of the landscape, from zoning tables and their parameters. Our expectation is that after this important step of programming and modeling work developed, there will be a basis for supporting municipal governments and community control and management of the urban landscape, with a view to promote, in fact, designed spaces within the parameters of sustainability.

\section{Acknowledgements}

We would also like to express our thanks to the former students of the Oficina de Planejamento Urbano: Problemas de Planejamento Local
URB018 (Urban Planning Workshop: Local Planning Problems) module, for their interest and involvement with the activities we proposed, and for having understood the importance of using geoprocessing in Urban Planning and Management.

\section{References}

LYNCH, Kevin. A IMAGEM DA CIDADE. Cidade de São Paulo: Editora Martins Fontes. 1997.

CULLEN, Gordon. PAISAGEM URBANA. Cidade de Lisboa e do Rio de Janeiro: Editora Edições 70. 1983. 